\title{
Influence of body water distribution on skin thickness: measurements using high-frequency ultrasound
}

\author{
C.EISENBEISS, J.WELZEL, W.EICHLER* AND K.KLOTZ* \\ Departments of Dermatology and *Anaesthesiology, Medical University of Lübeck, Ratzeburger Allee 160, D-23538 Lübeck, Germany
}

\begin{abstract}
Background Although it is known that the skin acts as a water reservoir and participates in the fluid content of the whole body, no method has been established to quantify the fluid shifts in superficial tissue.

Objectives The aim of this study was to investigate changes in dermal and subcutis thickness and echodensity at the forehead and lower leg by high-frequency $(20 \mathrm{MHz})$ ultrasound under various physiological conditions influencing water balance.

Methods These parameters were measured in the skin of 20 healthy male volunteers at baseline and successively at $30 \mathrm{~min}$ after lying down, in a head-down position, after physical activity and after infusion of $10 \mathrm{~mL} \mathrm{~kg}{ }^{-1}$ body weight of Ringer's solution.

Results Dermal thickness at the forehead showed a significant increase from baseline to a horizontal position and a further increase in the head-down position. Physical activity did not lead to further changes, whereas after fluid infusion the dermal thickness also increased markedly. The echodensity showed inverse changes, with decreasing values. The thickness of the subcutis increased slightly from baseline to a lying position and decreased in the head-down position and after fluid infusion. At the lower leg, skin thickness decreased slightly in the head-down position with elevated legs, and increased after fluid infusion.

Conclusions Our results show that slight changes in the water distribution of the body influence the thickness and the echodensity of the dermis. Changes are more pronounced at the forehead than on the lower legs. Further, the fluid storage takes place mainly in the dermis and not in the subcutis. High-frequency ultrasound is able to quantify these effects and is a sensitive method for measuring fluid intake and balance during anaesthesia and therapy.
\end{abstract}

Key words: 20-MHz ultrasound, body position, fluid shifts, skin thickness, water balance

Physiological influences on skin thickness include age, sex, time of day, body posture and sex hormones during the menstrual cycle and pregnancy. High-frequency $(20 \mathrm{MHz})$ ultrasonography enables non-invasive evaluation of these changes in skin thickness and echodensity. ${ }^{1-4}$ Intrinsic skin ageing is accompanied by a decrease in skin thickness due to a reduction of water content, proteins and collagen. ${ }^{5}$ The skin thickness of the lower body regions increases from morning to evening. ${ }^{6}$ Higher oestrogen and progesterone levels in the second phase of the menstrual cycle lead to increasing water retention in the dermis, and further influence of sex hormones is evident in the third trimester of pregnancy, when skin thickness increases by $10 \%$ or more. ${ }^{7}$ Experimental studies have also shown localized increasing skin thickness due to histamine-induced oedema. ${ }^{8}$ Furthermore, skin thickness is influenced by diseases of the cardiac system and by kidney function. Dermal oedema induced by chronic venous insufficiency assessed by high-frequency ultrasound showed decreasing echogenicity due to water retention. ${ }^{9}$

Skin thickness is dependent on the amount of collagen fibres, cellular substances and interstitial fluid content. Fluid content of the skin determines biophysical properties such as turgor, elasticity and distensibility. Further, the skin participates in the fluid content of the whole body. ${ }^{10,11}$ Water is bound to hyaluronic acid, glycosaminoglycans and proteoglycans. ${ }^{12}$ Increasing fluid content leads to a greater skin thickness. This is visible by eye when the increase reaches about $50-100 \%$. Increasing fluid content in 
the dermis leads to disarrangement of collagen bundles and results in a loss of echodensity. Measurements of decreasing echodensity after water retention by ultrasound have been confirmed by nuclear magnetic resonance (NMR) spectroscopy. ${ }^{13-16}$

Until now, objective and sensitive parameters for measuring interstitial volume changes within the body have not been available. We have used highfrequency $20 \mathrm{MHz}$ sonography as a non-invasive procedure for studying cutaneous water. ${ }^{3,4}$ The aims of the study were to answer the following questions. Are slight changes in the fluid distribution detectable by $20-\mathrm{MHz}$ sonography? Does this effect lead to changes in thickness and echodensity of the dermis? In which layer of the skin does fluid storage take place?

\section{Subjects and methods}

Subjects

Twenty healthy male volunteers (age 24-37 years, weight $62-94 \mathrm{~kg}$ and normal body mass index) entered the study after ethics committee approval and informed consent.

\section{Measurements}

Cross-sectional b-mode scans were obtained with a 20-MHz ultrasound system (Dermascan C; Cortex Technology, Hadsund, Denmark). False-colour images represented the skin to a depth of $10 \mathrm{~mm}$. The waterfilled tank with the transducer was closed by a membrane and coupled on the skin surface with a layer of gel. The axis of the probe was taken strictly perpendicular to the surface of the skin. We performed only one measurement at each location, because the coefficient of variation of repeated measurements is reported to be low (about $2 \cdot 2 \%$ on normal skin). ${ }^{16}$ The thickness of the gel layer was adjusted to about $1 \mathrm{~mm}$. The gain/compensation curve was adjusted to a horizontal position at $22 \mathrm{~dB}$. The lateral resolution at $20 \mathrm{MHz}$ is about $200 \mu \mathrm{m}$, and the axial resolution about $80 \mu \mathrm{m}$. Thickness of the dermis was determined in b-mode, excluding the hyperechogenic entrance echo and the hypoechogenic subcutis. Echodensity (the average amplitude of the echoes in a defined area of the image) was determined in a region of interest. In a chosen area, including the whole dermis, the amplitudes of the echoes of the single image elements (pixels) were ascribed to a numerical scale (0-255).
Values are given without dimension. Ultrasonic measurements were performed by the same investigator under constant environmental conditions.

The measurements were performed in the morning, at the same time of day, and successively at the following times: (1) at baseline, in a lying position; (2) after $30 \mathrm{~min}$ in a lying position; (3) after $30 \mathrm{~min}$ in a head-down position; (4) after $30 \mathrm{~min}$ of strong physical activity (jogging); and (5) $30 \mathrm{~min}$ after infusion of $10 \mathrm{~mL} \mathrm{~kg}{ }^{-1}$ body weight of Ringer's solution given over $15 \mathrm{~min}$. Haematocrit and body weight were determined respectively before and after intravenous infusion of Ringer's solution.

The measurements of thickness and echodensity were performed at both the middle of the forehead and the lower leg (right and left side at the proximal pretibial region). Additionally, measurements at the subcutis were also obtained at the forehead. At this location ultrasound is reflected at the underlying hyperechogenic bone and allows measurements of the dermis and the thin subcutis.

\section{Statistical analysis}

The results are represented as mean (as percentage of the initial value) \pm SEM for all measuring points. Data were analysed by Wilcoxon signed-rank test for matched pairs. The chosen level of significance was $P<0 \cdot 05$.

\section{Results}

\section{Forehead}

The thickness of the dermis at the forehead $(100 \%)$ showed an increase to about $107 \%$ from baseline (1) to a horizontal position (2) and to $109 \%$ to a head-down position (3). After physical activity (4), skin thickness remained nearly unchanged. Thirty minutes after fluid infusion (5), thickness increased to $116 \%$. All changes in dermal thickness were significant $(P<0 \cdot 01)$ in comparison with the values at baseline.

Echodensity decreased from baseline (1) to a horizontal position (2) to $90 \%$ and in a head-down position (3) to $85 \%$. After physical activity (4) an increase to $86 \%$ was observed. After fluid infusion (5) the echodensity values remained at $85 \%$. All changes were significant $(P<0.05)$ in comparison with the values at baseline.

The thickness of the subcutis increased from baseline (1) to a horizontal position (2) to $105 \%$, 


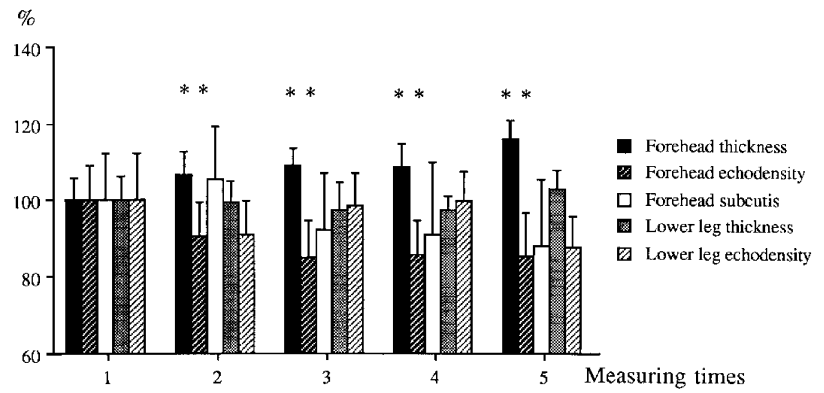

Figure 1. Changes in skin thickness and echodensity at the forehead and thickness of the subcutis of the forehead at the five measuring times as well as changes in skin thickness and echodensity at the lower leg (\%, mean \pm SEM). Significant differences from the values at the first measurement are marked by asterisks. 1, arrival (baseline); 2 , after $30 \mathrm{~min}$ lying; 3, after $30 \mathrm{~min}$ head-down; 4, after $30 \mathrm{~min}$ jogging; 5, 30 min after intravenous Ringer's solution.

decreased in a head-down position (3) to $92 \%$, remained at $91 \%$ after physical activity (4), and decreased after fluid infusion (5) to $88 \%$. These results were not significant.

The results are shown in Figure 1. Figure 2 shows $20-\mathrm{MHz}$ ultrasound of the skin of the forehead at baseline and after fluid infusion.
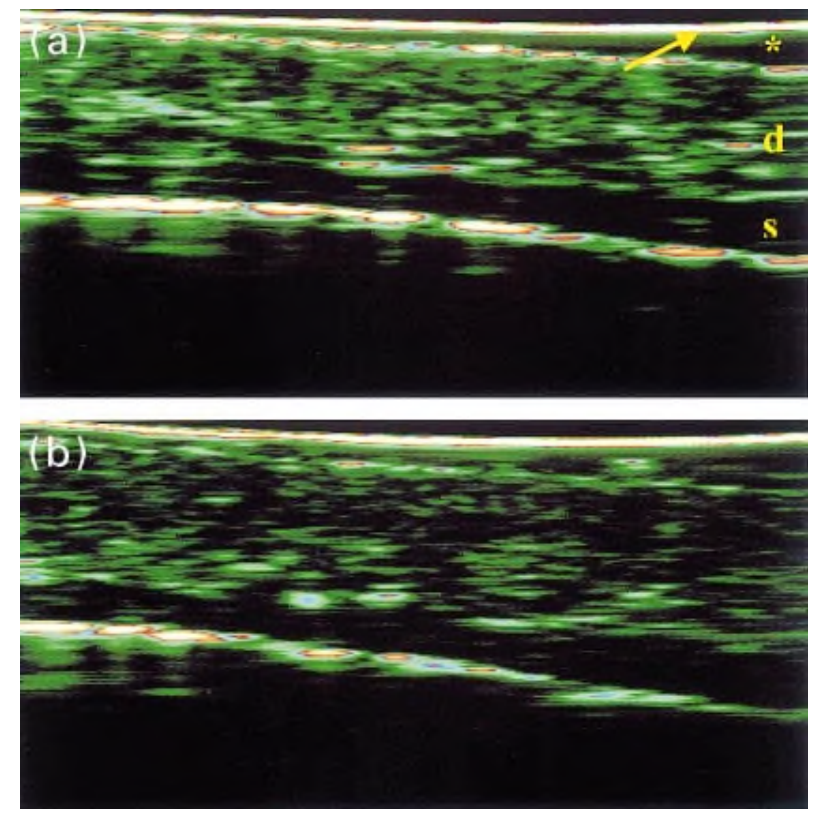

Figure 2. (a) $20-\mathrm{MHz}$ ultrasound of the skin of the forehead at baseline. Skin thickness (i.e. corium-the distance between entry echo and subcutis) $2.18 \mathrm{~mm}$, echodensity 8 . Arrow, membrane; asterisk, gel layer; d, echo-dense dermis; s, echo-poor subcutis. (b) $20-\mathrm{MHz}$ ultrasound of the skin of the forehead of the same subject after fluid infusion. Skin thickness increased markedly $(2 \cdot 49 \mathrm{~mm})$ in comparison with (a), while echodensity decreased to 5 .
Lower leg

From baseline (1) to a horizontal position (2) the skin thickness decreased to $99 \%$ (not significant), in a headdown position (3) with elevated legs to $97 \%$, remained unchanged after physical activity (4) and increased after fluid infusion (5) to $103 \%$. The changes were significantly different at time points 2,3 and 4 in comparison with time point 5 . Echodensity showed decreasing values when thickness of the dermis increased and vice versa (not significant). The results at the lower legs are shown in Figure 1.

\section{Discussion}

The connective tissue of the skin is crucial for water storage in the body. The skin tissue volume of a man with a body weight of $70 \mathrm{~kg}$ is about $7 \mathrm{~L}$. The extracellular matrix comprises two-thirds of this volume, and consists of about $50 \%$ fluid. Thus, onethird of the tissue layer consists of interchangeable water. ${ }^{17}$ Proteoglycans, a major component of the extracellular matrix, can bind one-third of the total interstitial amount of fluid.

The interstitial fluid volume depends on the capillary and postcapillary venous pressure as well as on the interstitial hydrostatic pressure, and is further determined by plasma colloid osmotic pressure, concentration of electrolytes and permeability of the capillary wall. ${ }^{18}$ Increasing capillary hydrostatic pressure and decreasing colloid osmotic pressure or increased permeability of the capillary wall leads to increasing fluid shift from the intravascular space to the interstitial tissue. Following the Starling mechanism, this is in balance with lymphatic flow. Impairments due to diseases of the cardiac system or the kidney, or excessive fluid infusion regimens, lead to increasing interstitial volume and oedema.

In this study we have shown that $20 \mathrm{-MHz}$ sonography enables in vivo evaluation and quantification of slight physiological changes in skin thickness. These are induced by water retention or dehydration. Our results showed increasing skin thickness at the forehead and the lower leg after fluid infusion. At the forehead it increased by $16 \%$. In a position with elevated legs, the thickness of the pretibial compartment decreased; skin thickness at the lower leg showed a variation of up to $6 \%$. In prior studies, changes in skin thickness of about $7 \%$ were recorded during the menstrual cycle of women. These are not evident by eye, but are detectable with high-frequency ultrasound. 
Water retention during pregnancy can also be measured by skin ultrasound. Changes in skin thickness of about $10 \%$ occur in women before and after delivery. Therefore, both early oedema and gestosis can be recognized preclinically. ${ }^{7}$

Marked changes in skin thickness were recognized after haemodialysis by Brazelli et al., ${ }^{19}$ who recorded a decrease of about $25 \%$. These findings are in agreement with our results: increasing weight after fluid infusion is accompanied by significantly increasing skin thickness.

At every measuring event of our study it was observed that increasing skin thickness was accompanied by decreasing echodensity. This is in agreement with previous measurements. Comparative studies of dermal water using NMR spectroscopy and $20-\mathrm{MHz}$ ultrasound have shown that dermal water content is directly negatively correlated with dermal echogenicity. $^{4,14,15}$ The effect is due to the disarrangement of the collagen bundles by interstitial oedema which leads to a decrease in the strong echogenicity of the dermis.

The volume shift occurs in a very short time. In blood donors it has been demonstrated that $36 \%$ of the donated blood was replaced by interstitial fluid in a few minutes. ${ }^{20}$ In tilt manoeuvres Kirsch et al. ${ }^{21}$ showed that volume shifts within superficial tissues occur in two phases: in the first $5 \mathrm{~s}$ after changing position a rapid volume shift occurs, followed by a very slow volume change. During haemodialysis, several litres of fluid are shifted from one compartment to another in a few hours. ${ }^{22}$ In our experiments fluid shift also occurred rapidly, within $30 \mathrm{~min}$.

In this study we were able to demonstrate that water storage takes place in the dermis, which has a very rich arteriolar and venular supply, and not in the subcutis, which showed no significant changes at the forehead. Our results clearly show that fluid shift depends on the position of the body. This is in agreement with measurements in tilt manoeuvres using $10-\mathrm{MHz}$ ultrasound, which gave rise to thinner skin above and thicker skin below the heart indifferent point (this is directly below the apex of the heart), ${ }^{21}$ while at this point no skin thickness change could be measured.

The influence of gravity on the skin is detectable by ultrasound even before it is visible. Thus detection of signs of mountain sickness such as lung oedema is possible at an early stage. ${ }^{23}$ In a microgravity environment, Kirsch et al. ${ }^{24}$ recorded variations of about $20 \%$ in skin thickness using $10-\mathrm{MHz}$ ultrasound. This was confirmed by measurements of Diridollou et al. ${ }^{25}$ performed with 20-MHz ultrasound.
Our measurements demonstrated that highfrequency sonography of the dermis enables noninvasive, real time and in vivo monitoring of water balance between different compartments of the body. Furthermore, we have shown that fluid is stored in the upper dermis and not in the subcutis. Hence, it is clear that the skin acts as one of the major water reservoirs of the body. For clinical applications $20 \mathrm{MHz}$ ultrasound is a sensitive method for monitoring fluid intake during therapy and anaesthesia.

\section{References}

1 Altmeyer P, Hoffmann K, Stücker M. General phenomena of ultrasound in dermatology. In: Ultrasound in Dermatology (Altmeyer P, El-Gammal S, Hoffmann F, eds). Berlin: SpringerVerlag, 1992; 55-79.

2 Serup J, Keiding J, Fullerton A et al. High-frequency ultrasound examination of skin: introduction and guide. In: Handbook of Non-Invasive Methods and the Skin (Serup J, Jemec GBE, eds). Boca Raton: CRC Press, 1995; 239-56.

3 Gniadecka M. Non-invasive methods for determination of oedema and water behaviour in the skin. Skin Res Technol 1995; 1: 55-60.

4 Gniadecka M. Potential for high-frequency ultrasonography, nuclear magnetic resonance, and Raman spectroscopy for skin studies. Skin Res Technol 1997; 3: 139-46.

5 Seidenari S, Pagnoni A, Di Nardo A, Gianetti A. Echographic evaluation with image analysis of normal skin: variations according to age and sex. Skin Pharmacol 1994; 7: 201-9.

6 Gniadecka M, Serup J, Söndergaard J. Age-related diurnal changes of dermal oedema: evaluation by high-frequency ultrasound. Br J Dermatol 1994; 131: 849-55.

7 Eisenbeiß C, Welzel J, Schmeller W. The influence of female sex hormones on skin thickness: evaluation using $20 \mathrm{MHz}$ sonography. Br J Dermatol 1998; 139: 462-7.

8 Agner T, Damm P, Skouby SQ. Menstrual cycle and skin reactivity. J Am Acad Dermatol 1991; 24: 566-70.

9 Hu D, Phan TT, Cherry GW, Ryan TJ. Dermal oedema assessed by high frequency ultrasound in venous leg ulcers. $\mathrm{Br} J$ Dermatol 1998; 138: 815-20.

10 Aukland K. Interstitial fluid balance in experimental animals and man. Adv Microcirc 1987; 13: 110-23.

11 Guyton AC, Hall JE. The body fluid compartments: extracellular and intracellular fluids; interstitial fluids and oedema. In: Textbook of Medical Physiology (Guyton AC, Hall JE, eds), 9th edn. Philadelphia: W.B.Saunders, 1996; 297-313.

12 Knaus R, Fleischer G, Grunder W et al. Pulsed field gradient NMR and nuclear magnetic relaxation studies of water mobility in hydrated collagen. Magn Reson Med 1996; 36: 241-8.

13 Richard S, Querleux B, Bittoun J et al. Characterization of skin in vivo by high resolution magnetic resonance imaging: water behaviour and age-related effects. I Invest Dermatol 1993; 100: 705-9.

14 Gniadecka M, Quistorff B. Assessment of dermal water by highfrequency ultrasound: comparative studies with nuclear magnetic resonance. Br J Dermatol 1996; 135: 218-24.

15 Idy-Peretti I, Bittoun J, Alliot FA et al. Lymphedematous skin and subcutis: in vivo high resolution magnetic resonance imaging evaluation. J Invest Dermatol 1998; 110: 782-7. 
16 Agner T, Serup J. Individual and instrumental variations in irritant patch-test reactions - clinical evaluation and quantification by bioengineering methods. Clin Exp Dermatol 1990; 15: 29-33.

17 Aukland K, Reed RK. Interstitial-lymphatic mechanisms in the control of extracellular fluid volume. Physiol Rev 1993; 73: 1-78.

18 Parazynski SE, Hargens AR, Tucker B et al. Transcapillary fluid shift in tissues of the head and neck during and after simulated microgravity. J Appl Physiol 1991; 71: 2469-75.

19 Brazelli V, Borroni G, Vignoli GP et al. Effects of fluid volume changes during hemodialysis on the biophysical parameters of the skin. Dermatology 1994; 188: 113-16.

20 Fogh-Andersen N, Altura BM, Altura BT, Siggaard-Andersen O. Changes in plasma ionized calcium and magnesium in blood donors after donation of $450 \mathrm{ml}$ blood. Effects of hemodilution and Donnann equilibrium. Scand J Clin Lab Invest 1996; 56 (Suppl. 224): 245-50.
21 Kirsch KA, Merke J, Hinghofer-Szalkay H. Fluid volume distribution within superficial shell tissues along body axis during changes of body posture in man. Pflugers Arch 1980; 383: 195-201.

22 Berardesca E, Gabba P, Farinelli N et al. Skin extensibility time in women: changes in relation to sex hormones. Acta Derm Venereol (Stockh) 1989; 69: 431-3.

23 Gunga HC, Kirsch KA, Baartz FJ et al. Fluid distribution and tissue thickness changes in 29 men during 1 week at moderate altitude (2,315 m). Eur J Appl Physiol 1995; 70: 1-5.

24 Kirsch KA, Baartz FJ, Gunga HC et al. Fluid shifts into and out of superficial tissues under microgravity and terrestrial conditions. Clin Invest 1993; 71: 687-9.

25 Diridollou S, Pavy-Le A, Maillet A et al. Characterisation of gravity-induced facial skin oedema using biophysical measurement techniques. Skin Res Technol 2000; 6: 118-27. 